\title{
Design of mobile application for self-reporting affective experiences
}

\author{
Jari Jussila \\ Tampere University of \\ Technology \\ jari.j.jussila@tut.fi \\ Vilma Vuori \\ Tampere University of \\ Technology \\ vilma.vuori@tut.fi \\ Kari Suoja \\ Tampere University of \\ Technology \\ kari.suoja@tut.fi
}

\author{
Virpi Sillanpää \\ Tampere University of \\ Technology \\ virpi.sillanpaa@tut.fi \\ Mika Boedeker \\ Tampere University of Applied \\ Sciences \\ $\underline{\text { mika.boedeker@tamk.fi }}$ \\ Alberto Felicetti \\ University of Calabria \\ alberto.felicetti@unical.it
}

\author{
Nina Helander \\ Tampere University of \\ Technology \\ nina.helander@tut.fi \\ Jari Liukkonen \\ Tampere University of \\ Technology \\ jari.liukkonen@tut.fi \\ Cinzia Raso \\ University of Calabria \\ cinzia.raso@unical.it
}

\begin{abstract}
Affective experiences have a major role in value creation during customer encounters both in business to consumer (B2C) and business to business (B2B) domains. However, understanding and effectively identifying affective experiences is challenging. Based on a practical need of a case company, the aim of this study was to develop an ensemble artifact for measuring affective experiences during customer encounters. Following action design research method, we designed the artifact in two cycles. First cycle involved creating a poster to capture affective experiences in an event setting. In second cycle, a mobile application was developed for identifying affective experiences. In a pilot study the mobile application was used to interview 73 individuals during customer encounters at various touchpoints of the customer event by four interviewers. The study reports the preliminary findings, evaluates the artifact development process through the lenses of design science research process model, and identifies the future research directions.
\end{abstract}

\section{Introduction}

The significance of affective experiences in consumer behavior has long been a subject of research. However, in the B2B-sector their role has not been as salient as in the B2C-sector, although it has been argued that affective experiences sometimes have even bigger impact in the B2B context and understanding and managing these experiences is crucial form the value creation point of view. This kind of practical challenge was identified also by our case organization, an event organizer operating in B2B context. They had found out that emotions play a role in the overall customer experience and in the long run also in the overall value realization. However, they did not have appropriate tools to grasp this phenomenon, measure the affective experiences and to make their effect visible to their direct, paying customers. This kind of lack of tools is not surprising, as examining and understanding affective experiences is challenging, because the concept itself is ambiguous. For example, the use of the terms of various affective phenomena, such as "emotion", "feeling", "mood", "attitude", "affective", is in general rather loose and confusing [4, $23,30]$. In addition Scherer [30] points out, that there is no clear answer to the question of the number of different kinds of emotions.

In this kind of situation, it is crucial to clarify how the terms or concepts are used in each case. Affective experiences arise out of generation of emotions, feelings and moods [17]. In that sense affect is conceived as an umbrella concept [3]. Emotions can be considered as automatic, biologically determined and sub- or preconscious appearing in the beginning of the experience process. The later, conscious phase comprises personal feelings and moods. Further, moods are considered often e.g. milder, more enduring and whose cause or time of emergence is less well defined $[4,7,12,30]$. However, in this study the analysis is on the level of affective experience, not making distinction between emotions, feelings and moods. When necessary, emotions, feelings and moods can be distinguished according to their features of 
duration, intensity, control, cause, awareness, etc. [4, 7, $12,30]$. But the key question both for research and practical needs still remains the following: how to grasp affective experiences in such manner, that they are detected in a sufficient depth and precision but at the same time with a reasonable control over the instrument?

In this study, based on the need identified in practice, the aim is to design and develop an information systems (IS) artifact, which will serve as the instrument to grasp the affective experiences in a sufficient depth in order to support customer value creation. Theoretical base of the paper is built on the business and marketing literature on affective experiences, but the applied method is from IS literature as we follow the action design research (ADR) method [32]. The method combines benefits of design science research and action research, proposing an approach to design an IS artifact grounded on academic knowledge grasping advantages from a strong mutual interaction among academics, practitioners and end-users during the deployment of different releases of the artifact.

Furthermore, the whole research process is evaluated in the end of the paper through the lenses of design science research process (DSRP) model [27] through the phases of 1) problem identification and motivation, 2) setting the objectives of a solution, 3) the actual design and development, 4) demonstration, 5) evaluation and lastly, 6) communication.

\section{Theoretical bases of affective experiences for the design and development of the artifact}

The experiential aspect has for a long time been included in various studies of consumer behavior, already Stone [37] dealt with the issue. Later on Holbrook \& Hirschman [19] strongly highlighted the issue of experiences and Bitner [8] included emotional responses in her study of "servicescapes". The hedonistic or emotional component of perceived value is seen one or the main element in several other studies as well in B2C context. For example Bagozzi, Gopinath \& Nyer [4] state, that "emotions are ubiquitous throughout marketing" and Laros \& Steenkamp [24] presented a hierarchical consumer emotions model. There are also more practice oriented guidebooks of "emotional strategies and tactical action plans" for business success connected with a wider scope to marketplace and workplace application [18], as well as more specifically connected to customer experience, loyalty and value drivers [34]. Depending on the context, various affective experiences are investigated and highlighted. For example Shaw [34] presents twelve positive and eight negative affective experiences as value drivers related to customer loyalty.

In B2B context this kind of thinking and research does not exist to the same extent [9, 21, 22, 39]. Likewise, in organization science empirical research of emotions in work settings has been slow to enter the mainstream until the dawn of $21 \mathrm{st}$ century. Organizations are, however, intrinsically human entities [1, 2]. Similarly, as for example Tähtinen and Blois [39] point out, it would be deceptive to expect that people who are emotional consumers, leave all their emotions behind when they are in some role in the B2B-encounters (see also [22]). It has been argued that affective experiences sometimes have even bigger impact in the B2B context than in the B2C context because "there is more at stake" [10] and understanding and managing these experiences have even been named as the biggest competitive advantage [9]. People in B2B-encounters do have affective experiences while doing business with each other, those experiences may even dictate the outcome [18].

In this paper, affective experiences are related to the concept of customer value and thus should be taken into account and managed to enhance value creation. Shortly put, value creation is a process during which the customer and supplier interact and the sacrifices and benefits are evaluated, also in the experiential or hedonic level [36]. Understanding the affective experiences and the contexts in which they occur enables better controlling of the customer experience, value creation and, ultimately, behavior [18], both in $\mathrm{B} 2 \mathrm{C}$ and $\mathrm{B} 2 \mathrm{C}$ contexts.

One potential way to grasp the affective experiences proposed in the literature is the dimensional format. Dimensional format is convenient because answers to only two or three general dimensions, rather than multiple specific affective terms, are indicated. Based on the work of Mehrabian \& Russell [26], a three-dimensional PAD-framework for example nicely combines the three dimensions of affective experiences: the pleasure - non pleasure dimension, the arousal - non-arousal dimension and the dominance - non-dominance dimension. On the other hand, this format may be difficult because the dimensions are rather abstract and do not always correspond to the way one naturally talks about affective experiences [29].

Categorical and hierarchical approach provides more information over and above general dimensions, as discrete affective terms and their relationships with each other is captured [24] along with the possibility to use the natural way of talking about affective experiences [29]. However, it may be misleading to 
treat self-reports of sadness, anger, and the like, as discrete entities in the face of evidence that some individual's do not report them as discrete. Some individuals represent their experiences with a good deal of precision, whereas others represent their experiences in more global terms $[5,6,30]$. Thus, a practical framework to detect the affective experiences in various degrees of granularity is needed.

In the Figure 1 a combined solution is provided. As Fontaine [14] and Fontaine \& Scherer [15] point out, the different approaches are not mutually exclusive but rather complementary. First, the aforementioned threedimensional PAD-space is presented in a twodimensional pie-type graphic so, that each of the four pleasure-arousal combinations (elation, serenity, lethargy and tension) are further divided according to dominance to form eight "affective families".

In this way, more than just the general dimensions of positive and negative affect, pleasure and displeasure can be detected. Secondly, to make the framework correspond to the natural way of talking about affective experiences, the affective families need to be characterized by selected specific affective terms. The affective terms provided here represent a larger affective family and thus refer to a whole range of similar kind of terms. The terms are selected based on circumplex-type presentations [26], [33], [30], [31] and on lists of affective terms like for example in Laros \& Steenkamp [24], Meek [25] and Bradberry \& Greaves [11]. Finally, the underlying dimensional structure is important to locate the affective experiences to increase their manageability.

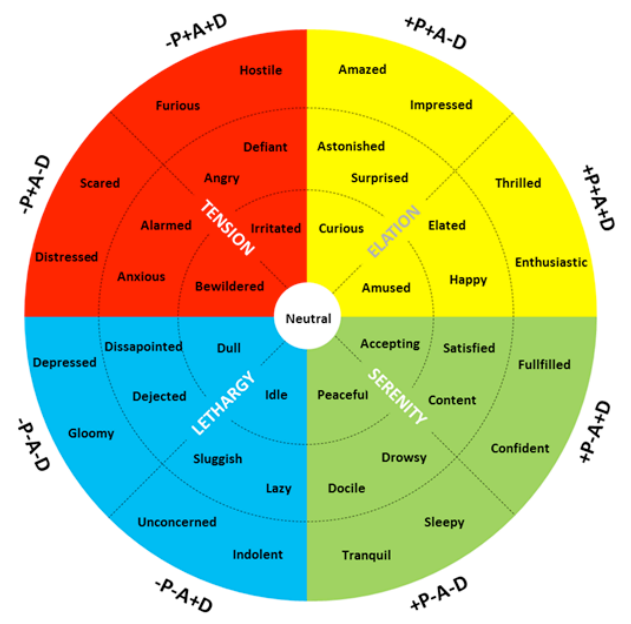

Figure 1. Framework for affective families [20].

When using the framework for empirical research purposes, the researcher has to decide, whether or not to make a distinction between emotions, feelings and moods and on which criteria (various criteria can be found for example in Bagozzi, Gopinath \& Nyer [4],
Beedie, Terry \& Lane [7], Derbaix \& Pham [12], Kokkonen [23] and Scherer [32]. Other forms of distinction might be relevant as well, for example if the experience is of social nature, for example pride, empathy, shame and embarrassment [3, 39]. For some purposes it is important to make the difference, because the difference may manifest itself as distinct causes or consequences of the experiences and therefore be sensitive to different managerial interventions. Additionally, the researcher has to decide if detecting the affective family is enough or if more precise distinction within the affective family is needed.

\section{ADR at Event Organizer}

This study employs action design science research [32] with the goal of developing an artifact for reporting affective experiences (Figure 2). In the problem formulation phase, the practical problem was the need of the event organizer company to have a solution for measuring affective experiences, which 1) could help in evaluating the success of customer events and in planning and designing of future events, and 2) would be easy for the end-users to use. The PAD framework was utilized as the theoretical basis for measuring affective experiences. Thus, the development of ensemble artifact was theoretically informed/based on theory of categorizing/identifying affective experiences [32]. The ADR team consisted of researchers and representatives from the $\mathrm{B} 2 \mathrm{~B}$ event organizer company. The roles and responsibilities of ADR team was planned in this phase; researchers brought the theoretical knowledge of identification of affective experiences and practitioners (event organizer) was responsible for arranging actual events where measurement would take place. Development of an ensemble artifact was part of a larger product development project, which secured long-term organizational commitment.

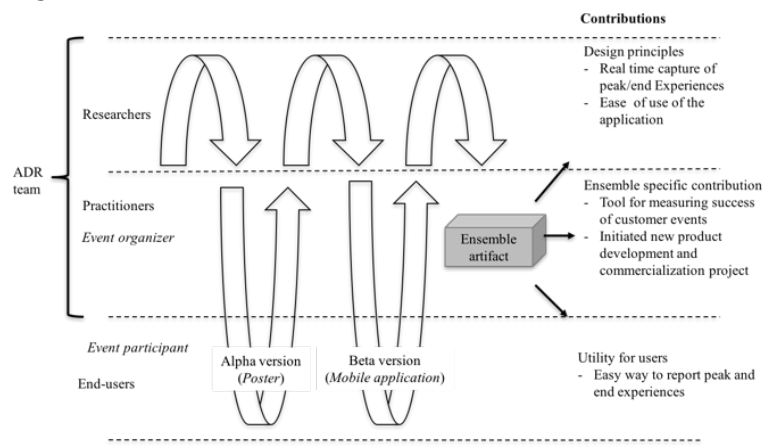

Figure 2. Research process used in the study (modified from [32]). 
The research was executed in two ADR cycles (resulting in alpha and beta version of the solution). In the first ADR cycle, the goal was set to evaluate the feasibility of PAD-framework for measuring affective experiences in customer encounters. To achieve this goal, a first version of the artifact for measuring affective experiences was to be developed and demonstrated in an international B2B event organized by the event organizer company. Evaluation was agreed to take place in a joint workshop with the researchers and the event organizer company representatives after the measurement were done, and post event feedback was received from the participants. On the condition of success of the first ADR cycle, a second ADR cycle would follow to design and demonstrate an improved version of the artifact that would be easy for the end-users to use and that could be used evaluate, which affective experiences most impact the success of organized customer events.

\subsection{First ADR cycle}

In the first ADR cycle the feasibility of PADframework was demonstrated and evaluated in measuring affective experiences of visitors in large international B2B event in travel industry organized by the case company. Before the actual event, researchers and practitioners (event organizers) had planning meetings related to both technical aspects of the artifact (poster) and organizational and contextual factors to be taken into account in the measurement. The co-operation and influential roles enabled mutual learning among project participants (c.f. [32]). For example, terms of affective experiences in posters and measurement points were discussed with practitioners to ensure that implementation of measurement is feasible in the event.

For many travelling companies, the event is the most important of the year. According to one travelling company representative, leads and business contacts created in the event may generate $80 \%$ of the sales of the company for the following year. The event lasts for 8 hours, and it has $600-800$ visitors. Visitors can be identified into three groups: buyers, sellers and bloggers. From measurement point of view, sellers were the most important group. The aim of the measurement of customer experience in the event was to create understanding about affective experiences that arises in the event, and what is the relevance of those experiences. In addition, the aim was to find out what are the strengths and weaknesses of the event.

The measurement was conducted by using posters in which visitors marked with stickers the term that corresponded their experience the best. Each visitor group had their own colors of the stickers, which enabled the analysis of differences between different groups. Measurement was conducted in two points of time: at arrival and exit in the event. In the first measurement point, the aim was to survey affective experience of visitors at the arrival, i.e. before the actual event. The second measurement point clarified affective experiences at the end of the event, i.e. what type of affective experiences the event had created. This type of measurement is able to provide information about affective experience in a certain point of time. Researchers guided end-users in measurement points (explained terms if necessary), and both researchers and practitioners evaluated the implementation of measurement both concurrently and after the event (c.f. authentic and concurrent evaluation, [19]. Thus researchers were able to do minor modifications during the measurement, for example change locations of measurement points. Endusers also gave verbal feedback during the event, e.g. commenting the need for a digital measurement instrument.

Researchers and practitioners evaluated the measurement results afterwards, aiming at reflecting the results and analyzing lessons learned for the future development. The measurement resulted in 272 replies at arrival and 158 replies in the exit. At the arrival, enthusiastic, happy and curious were the most reported affective experiences (Figure 3). In the exit, the most reported terms were enthusiastic, satisfied and happy (Figure 4). Based on this, we can for instance notice that the volume of affective experiences shifted from happiness to satisfaction during the event.

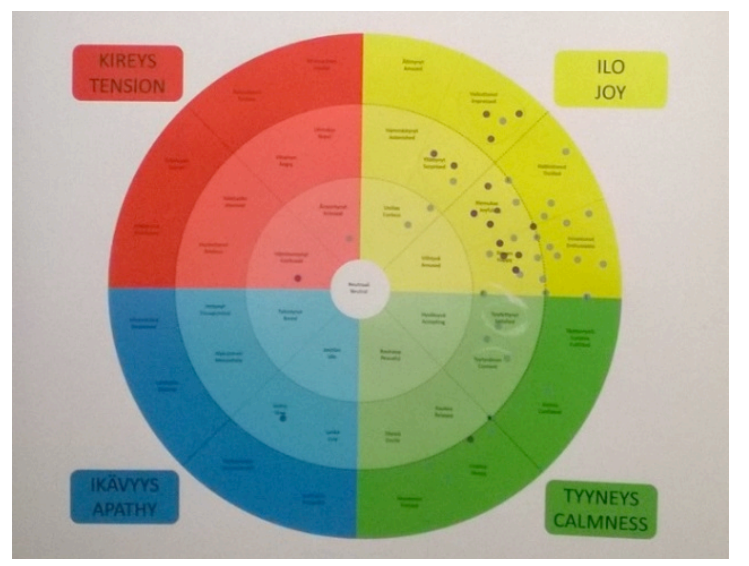

Figure 3. Affective experiences at the moment of arrival to the event. 


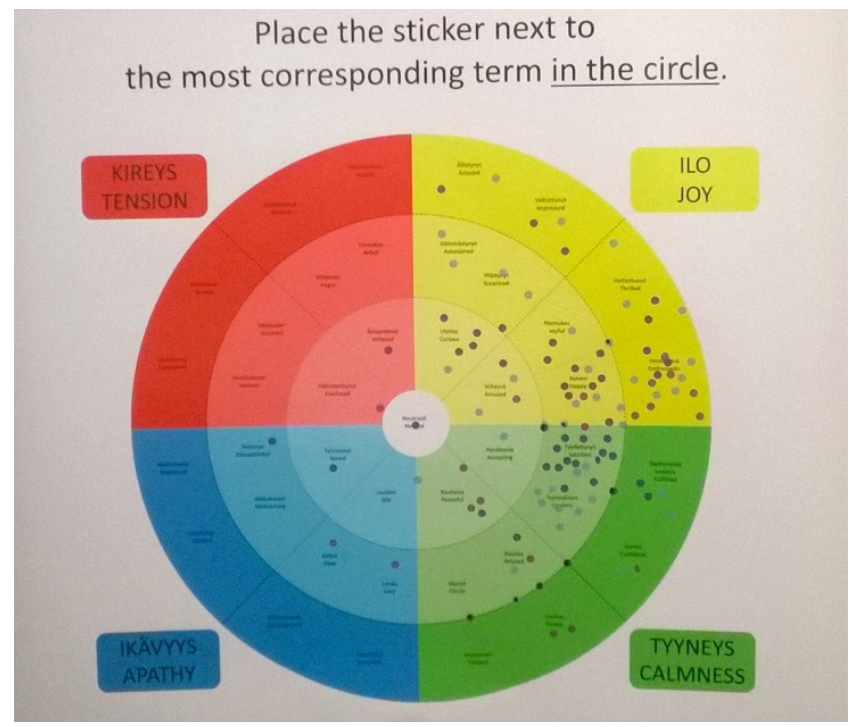

Figure 4. Affective experiences at the moment of departure from the event.

One of the limitations of this measurement approach was that visitors were not asked reasons for their experiences. Thus, there might have been reasons other than related to the event that caused the reported affective experiences. For example, visitor might have felt irritated at arrival, because of delay in the public transportation timetables. Thus, this caused some challenges for the validity of the measurement. Another limitation was that some participants found difficulties in finding suitable term to match their experience. Third, analysis of results was very timeconsuming, because it had to be done manually. Fourth, with this measurement approach, we could not identify the intensity of affective experiences (e.g. degree of feeling enthusiastic). Thus, the early evaluation of results enabled the increasing understanding of the ensemble artifact, both in terms of technical solution and way of organizing/implementing the measurement

\subsection{Second ADR cycle}

The problem formulation in the second ADR cycle, considered as input the lessons learned from the reflection and learning from the first ADR cycle, and emphasized the practitioners viewpoint of designing an end-user friendly measurement instrument to be implemented as a mobile application and that would focus on the affective experiences that most impact the success of customer events. In order achieve the set goal, the measurement instrument related to affective experiences was to be simplified, and additional elements/variables included that would enable evaluating the success of the customer event.
Based on the practitioners' earlier experiences of measuring success of customer events, and informed by theories investigated by the researchers' the additional elements to be added to the measurement instrument were jointly agreed. Net Promoter Score [28] for evaluating customer satisfaction, and Customer Effort Score [13] were considered the most relevant additional metrics. It was the practitioners view that all the scales should be the same, ranging from 0-10 (as in Net Promoter Score), and therefore it was decided to also measure the affective experiences using a scale ranging from $0-10$.

The goal of focusing on the affective experiences that most impact success of customer events was partly related to simplifying the measurement instrument, but also for understanding which affective experiences best correlate with chosen success measures (NPS and CES). Practitioners view was to reduce the amount of affective experience terms to three for each affective family, instead five terms originally used. Also, instead of selecting affective experience term that best describe the experience, the selection was to be done at affective family level. This was a defining moment, where in the building stage the ADR project actually forked into two projects. One ADR project would continue and accommodate the changes proposed by the practitioners, and also tailor the IT artifact to the user interface and experience design of the company. Another ADR project would follow the design choices of ADR researchers and that would result as an IT artifact to be released as open source. The open source mobile application is illustrated in Figure 5. However, the evaluation presented in this study (Table 1 and 2) is conducted on the ensemble artifact tailored for the practitioners.

In building of the IT artifact there was also mutual agreement between ADR researchers and practitioners on many of the requirements. These included e.g. electronic data collection and analysis (vs. manual in the alpha version), and easiness to use by many users/participants at the same time. Both agreed that to increase the validity of the measurement there was a need to capture the reasons behind the affective experiences. Also capturing the intensity of the affective experience with the mobile application was perceived important by both parties. For both practical and research reasons it was also agreed that the language support for several languages were to be built-in the mobile application, e.g. that the language could be changed easily during the event to match the language of the participant. The build mobile application is illustrated in Figure 5. 


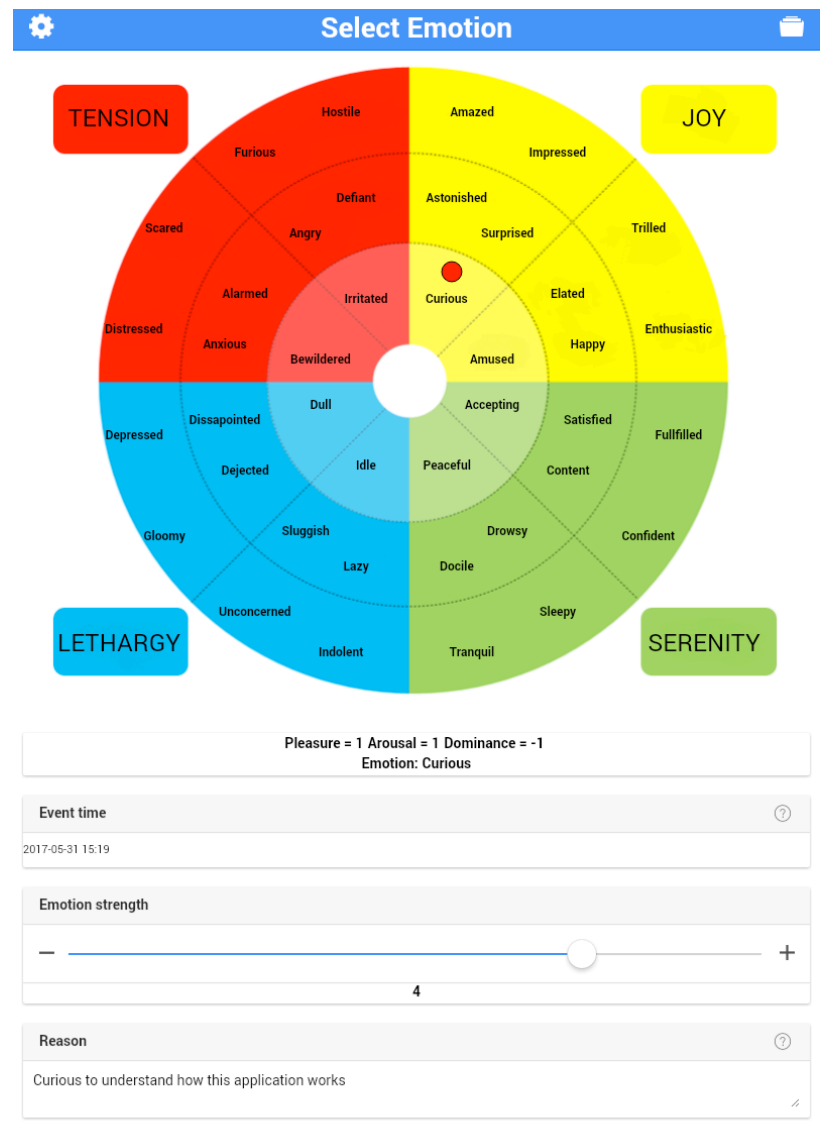

Save

Figure 5. Mobile application for reporting affective experiences.

All of the options on the mobile application are modifiable on the screen until saved (Figure 5). Event time is recorded by default as the moment when the affective experience term is selected from the wheel. However, one can modify the event time and e.g. report events that have happened in the past. After selecting the term, it's strength/intensity is given (on scale 1-5 in researcher version and on scale 1-10 in practitioner version). Lastly, the reason for the affective experience is documented. Once saved it is still possible to return to and edit the details from list view of events. The mobile application stores the data in a database, which makes the processing and further analysis of the recorded information convenient. This way, compared to the alpha version, the stored data can be easily combined with data collected with different kind of sensors, e.g. Moodmetric electrodermal activity ring that the company has experimented in B2B encounters [38]. An additional feature of selecting the touchpoint from four alternative locations was added to the tailored version of the event organizer. Each event was considered as a class, where various named touchpoints could be determined in advance, that could be then selected from the mobile application during the event.

Intervention stage was planned to take place during a large customer event. A customer event in the banking industry was chosen as the target for the intervention. The event took place during a single day, and approximately 1000 people attended the event. The goal was to measure 100 people during the event. The idea was to conduct two measurements, beginning with the measurement of affective experience with the mobile application and immediately following with a survey designed by the practitioners. It was decided that the measurements would be performed in pairs. Each pair would include a researcher and a practitioner. The role of the researcher was to instruct on the use of reporting the affective experience using the mobile application and the practitioner would follow-up with a survey.

In the first intervention step either the person being interviewed or the interviewer on behalf the interviewee selected the nearest corresponding affective experience of the recent encounter by using touch screen (see Figure 5) of a mobile device (Android tablet). In this case, there were four predetermined touchpoints from where the customer arrived for the interview. As a second step, the interviewees were asked to rate the intensity of the affective experience on a scale of 1-10 by using a slider. The third step included reporting the cause of the affective experience, i.e. what caused the affective experience in question.

Evaluation was done primarily concurrently with the intervention, and included noting down observations during the measurement and also in adhoc conversations with the end-users. For instance, one of the end-users of the mobile application, being a psychologist by trade, commented that first selecting an affective family and then reporting the intensity of an affective experience is confusing: "Which (affective experience) intensity am I supposed to report (from the three alternatives)?" Also one end-user found it problematic to evaluate the affective experience of a predefined touchpoint, and made the argument that in that touchpoint there were actually several encounters, of which he would give a different evaluation of each. Most people, however, found it easy to evaluate the affective experience using the mobile application. Measurement of affective experience with the mobile application took 1-2 minutes, whereas responding to the follow-up survey took 4-7 minutes. The follow-up survey was found to be too long and tiresome to answer. One of the respondents was willing to report 
his affective experience, but refused to answer to the follow-up survey entirely.

A short reflection was performed during building, intervention and evaluation (BIE) cycle, but a more detailed one was organized as workshop between the researchers and practitioners. In reflecting the measurement approach and going through the feedback received from end-users, several ways to improve measurement practice were devised. First, in case several customer encounters happen at predefined touchpoint, the respondent should be inquired to report the "peak" experience. Second, it was agreed by the researcher and practitioners that the measurement instrument was over-simplified by inquiring only the affective family, and not the intensity related to a specific affective experience term. This could be addressed in the future, either by instructing the interviewees to inquire also the closest matching affective experience term after selecting the affective family, or implementing a two step selection directly to the mobile application, where first the affective family is selected and then closest matching affective experience terms in that family is selected. In the workshop also the individual terms were discussed, and the original translations from English to Finnish related to the follow-up survey were especially iterated to make it more easier for the participants to respond to.

\section{Learning from the process: analysis of the results of the pilot studies}

Based on the pilot studies, we identified various benefits related to the mobile application. Mobile application can be modified according to situational requirements, for example, terms describing affective experiences are relatively easily modified based on the context (e.g. different terms can be used in different types of events). Theoretical framework (PAD) offers different sets of terms describing affective experiences, and suitable set of terms for different types of situations based on the theoretical framework can be selected. Compared to posters, mobile application benefits users by providing results in electronic form which facilitates the analysis of results. When using posters, respondents saw each other's replies, which may have affected the way respondents reported their affective experiences. Mobile application adds reliability of the measurement, since earlier responses do not affect the results that respondents give.

After the second ADR cycle both the ADR researchers and event organizer company representatives evaluated the results of the latest pilot study. Evaluation included conducting statistical analysis on the data collected with the mobile application against the goals set in the beginning. A joint workshop was then organized to analyze and discuss the results together.

As the goal of the event organizer was to understand, which affective experiences are more valuable, i.e. create more value for the customer, an analysis of measured affective experiences and corresponding Net Promoter Score (NPS) scores was conceived as one way to evaluate the success of the event. NPS is a well-known and often used metric [28] for evaluating customer satisfaction, and for this reason was one of the items included in the follow-up survey. See the cross-tabulated NPS scores and measured affective experiences in following Table 1.

Table 1. Cross-tabulated NPS scores and measured affective experiences.

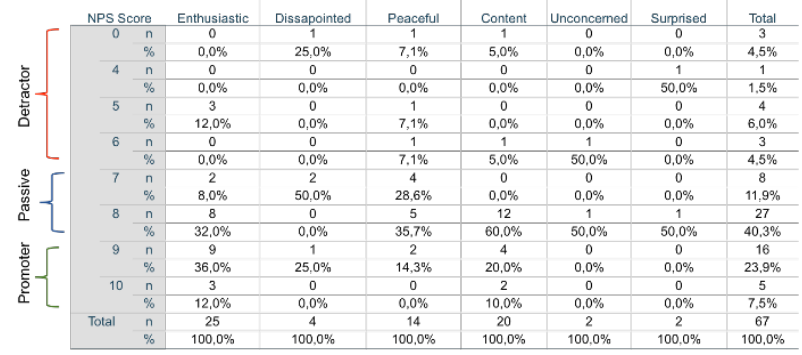

NPS score has also received critique, and some prefer using Customer Effort Score (CES) [13]. CES is measured by asking a single question: "How much effort did you personally have to put forth to handle your request?" and it is scored on a scale from 1 (very low effort) to 5 (very high effort) [13]. As this metric is not directly applicable to the event context, the event organizer had designed a similar metric, with the attempt to evaluate perceived customer effort. The observed affective experiences corresponding to this metric, were therefore also evaluated (Table 2).

Table 2. Cross-tabulated customer effort score (CES) and measured affective experiences.

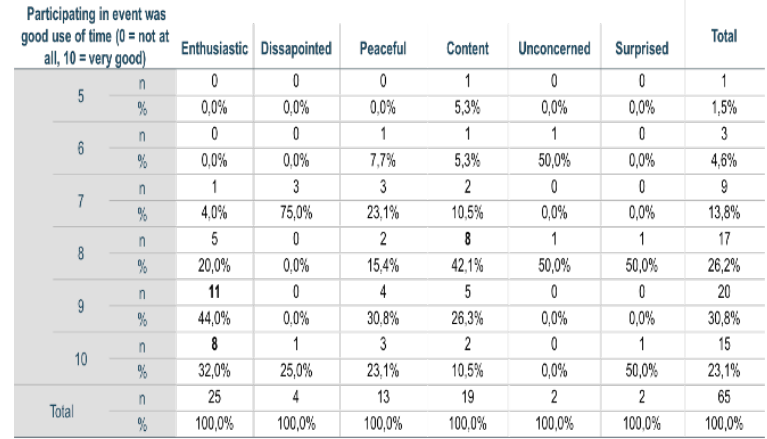


After the second cycle, some development needs were identified. For example, respondents were asked to select the sector including three terms that corresponds the best to their affective experience, and after that they were asked to assess the intensity of the experience. In this solution, it remained unclear which particular terms of these three was the one respondent had selected. Future developments of the mobile application can solve this issue, for instance, by adding a data field that enables registering which term is selected, or to describe a more appropriate term if the respondent meant some other term that was not included in the selection.

\section{Discussion and conclusions}

Our research pursued the goal of proposing a solution in the form of an IS artifact to practitioners' business problem related to understanding of customers' affective experiences, but also the goal of creating new scientific knowledge on measuring affective experiences, as it was identified as a gap in the earlier B2B research. We selected the ADR method [32] as the best suitable research approach to fulfill this kind of twofold objective of our research. The study provides contributions to the ensemble artifact being designed, to the utility of affective experience measurement to users, as well as, to general design principles.

We followed the ADR method in two iterative BIE cycles, the first represented by the poster version of the framework and the second represented by the developed mobile application. Our interventions were carried out in the customer events organized by our case company. In evaluating the utility of affective experience measurement both the poster and the mobile application were surprisingly positively received. For instance, none of the encountered customers refused to report their affective experiences using the mobile application and they found the mobile application easy to use and select an appropriate term matching their affective experience.

To reflect the overall results of the study, new ways of measuring affective experiences suitable to different context were generated through the ADR cycles, but still there were found some limitations. Poster was found useful in collecting affective experiences at the point of arrival or departure from the event, however, not capturing the reasons of affective experiences and their exact time and context of emergence. The mobile application could, however, be displayed on a huge screen that would allow also interactive user input and overcome the limitations of using a physical poster.
For interview based collection of affective experiences using the mobile application on a tablet was found as a convenient way to record the experiences. In the design of the mobile application also a third scenario was considered, where the user could download the application and use it with his personal mobile phone to self-report affective experiences.

Although the artifact was developed in this study in the special context of customer events in $\mathrm{B} 2 \mathrm{~B}$ markets, we still can draw some careful generalizations based on the experiences of the study. For example, the following uses cases can be identified for the developed mobile application:

- companies can use the mobile application to collect customer experiences during customer encounters, either by interviewing the customers or letting the customers to selfreport the affective experience of e.g. a customer support situation

- researchers can use the application to collect affective experiences in a variety of context, as well as, to collect data to further develop theoretical and conceptual models

- individuals can use the mobile application to collect qualitative data on their wellbeing and to combine it with data collected by sensors, such as e.g. the heart rate variability [16] and electrodermal activity [38]

The main design principles derived from the study include real time capture of peak/end experiences, as well as, simplicity and ease of use of the application. Real time capture of peak/end experiences enables cost-efficient measuring of success of events and supports planning of events. However, without interviewer involvement (human contact) valuable information can be lost that could help to improve both events and their measurement. Simplicity and ease of use of the application allow user-friendly capture of affective experiences and in a larger compared to using traditional survey instruments. However, oversimplification, e.g. reducing measurement to affective family level, risks losing information and accuracy regarding experiences making it difficult to evaluate, which experiences most impact the success of event.

In its current form the developed artifact can already serve in multiple exploratory purposes, but in order to fully benefit from it in the afore identified practical use cases there still needs to be further testing in different real-life contexts and empirically grounded development work. The key question for the practice and for the use in business purposes is that how are the affective experiences realized in creating value for the business [35]. Thus, the relationship between the 
affective experiences and the value creation should be in the focus of practically oriented studies in future.

For the overall evaluation of the study presented in this paper we'll use the six phases of DSRM process [27].

Firstly, the problem identification and motivation originated especially from the practical need of our case company, but also from identification of theoretical gap for affective experiences in earlier B2B marketing research.

Secondly, based on the identification of this kind of practical problem and motivation stemming out from the theoretical gap, we set the objectives for the solution. The main objective was to create an IS solution, specifically a mobile app, that would be easyto-use but still offer appropriate knowledge on affective experiences of the selected actors (e.g. customers, employees). These objectives were set together among the researchers and the practitioners from the case company.

Thirdly, within the design and development phase we followed the ADR model, which couples the practice and theory levels nicely, and further allowed the interaction between the researchers and the case company, but also with the actual end users of the application (in this case the customer participating in the events organized by the case company). This phase was carried out iteratively along with the fourth phase, demonstration, which involved demonstrating and testing the developed application (and in the first phase of the ADR process also the poster version of the framework) within real-life case events.

Based on the testing and the feedback data received from the users of the application we were able to carry out the initial evaluation of the developed mobile application. When mirroring the feedback to the objectives set in the beginning of the process, it seems that the main objective of the easiness of use was able to be achieved.

The last phase of the process, communication, is still under way. This paper is part of the initial steps for communicating the designed and developed artifact. In overall, the designed and developed artifact at its current form offers a good starting point and an easy to use tool for gaining more in-depth understanding of the affective experiences of individuals.

As, based on our study, the developed IS artifact is perceived by the users as an easy way to report both the ad hoc peak experiences and the perceived end experience, this could indeed be a delivery mechanism for an instrument to capture affective experiences in B2B context and thus, contribute to instrument development discourse in IS literature. However, as there are challenges especially in the theoretical background of affective experiences and the measurement of them, there still needs to be carried out a lot of more evaluative research in the future.

\section{References}

[1] Ashkanasy, N.M. Emotions in organizations: A multi-level perspective. In Multi-level issues in organizational behavior and strategy. Emerald Group Publishing Limited, 2003, 9-54.

[2] Ashkanasy, N.M., Humphrey, R.H., and Huy, Q.N. Integrating Emotions and Affect in Theories of Management. Academy of Management Review 42, 2 (2017), 175-189.

[3] Bagozzi, R.P. The role of social and self-conscious emotions in the regulation of business-to-business relationships in salesperson-customer interactions. Journal of Business \& Industrial Marketing 21, 7 (2006), 453-457.

[4] Bagozzi, R.P., Gopinath, M., and Nyer, P.U. The role of emotions in marketing. Journal of the academy of marketing science 27, 2 (1999), 184-206.

[5] Barrett, L.F. Discrete emotions or dimensions? The role of valence focus and arousal focus. Cognition \& Emotion 12, 4 (1998), 579-599.

[6] Barrett, L.F. Feelings or words? Understanding the content in self-report ratings of experienced emotion. Journal of personality and social psychology 87, 2 (2004), 266.

[7] Beedie, C., Terry, P., and Lane, A. Distinctions between emotion and mood. Cognition \& Emotion 19, 6 (2005), 847-878.

[8] Bitner, M.J. Servicescapes: The impact of physical surroundings on customers and employees. The Journal of Marketing, (1992), 57-71.

[9] Blount, J. Customer experience is the most powerful competitive advantage for B2B companies. Business Know-How, 2016.

http://www.businessknowhow.com/marketing/custexp. htm.

[10] Bozek, S. Customer journey mapping in B2B. CustomerThink, 2015.

http://customerthink.com/customer-journey-mappingin- $b 2 b /$.

[11] Bradberry, T. and Greaves, J. Emotional Intelligence 2.0. TalentSmart, 2009.

[12] Derbaix, C. and Pham, M.T. Affective reactions to consumption situations: A pilot investigation. Journal of Economic Psychology 12, 2 (1991), 325-355. 
[13] Dixon, M., Freeman, K., and Toman, N. Stop trying to delight your customers. Harvard Business Review 88, 7/8 (2010), 116-122.

[14] Fontaine, J. The dimensional, basic, and componential emotion approaches to meaning in psychological emotion research. In Components of emotional meaning: A sourcebook. Oxford University Press, 2013, 31-45.

[15] Fontaine, J. and Scherer, K. The global meaning structure of the emotion domain: Investigating the complementarity of multiple perspectives on meaning. In Components of emotional meaning: A sourcebook. Oxford University Press, 2013, 106-125.

[16] Franssila, H., Okkonen, J., and Savolainen, R. Developing measures for information ergonomics in knowledge work. Ergonomics 59, 3 (2016), 435-448.

[17] Gentile, C., Spiller, N., and Noci, G. How to sustain the customer experience:: An overview of experience components that co-create value with the customer. European Management Journal 25, 5 (2007), 395-410.

[18] Hill, D. Emotionomics: Leveraging emotions for business success. Kogan Page Publishers, 2010.

[19] Holbrook, M.B. and Hirschman, E.C. The experiential aspects of consumption: Consumer fantasies, feelings, and fun. Journal of consumer research 9, 2 (1982), 132-140.

[20] Jussila, J., Boedeker, M., Jalonen, H., and Helander, N. Social media analytics empowering customer experience insight. In Strategic Innovative Marketing, 5th IC-SIM, Athens, Greece 2016. 2017.

[21] Kiely, J.A. Emotions in business-to-business service relationships. The Service Industries Journal 25, 3 (2005), 373-390.

[22] Knight, L. Proving the Value of Emotion in B2B Marketing Communications. Upshot Agency News, (2012).

[23] Kokkonen, M. Ihastuttavat, vihastuttavat tunteet. Opi tunteiden säätelyn taito. Jyväskylä: PS-kustannus, (2010).

[24] Laros, F.J. and Steenkamp, J.-B.E. Emotions in consumer behavior: a hierarchical approach. Journal of business Research 58, 10 (2005), 1437-1445.

[25] Meek, W. Processing emotions. 2011.

[26] Mehrabian, A. and Russell, J.A. An approach to environmental psychology. the MIT Press, 1974.
[27] Peffers, K., Tuunanen, T., Rothenberger, M.A., and Chatterjee, S. A design science research methodology for information systems research. Journal of management information systems 24, 3 (2007), 45-77.

[28] Reichheld, F.F. The one number you need to grow. Harvard business review 81, 12 (2003), 46-55.

[29] Sacharin, V., Schlegel, K., and Scherer, K.R. Geneva Emotion Wheel rating study (Report). Geneva, Switzerland: University of Geneva. Swiss Center for Affective Sciences, (2012).

[30] Scherer, K.R. What are emotions? And how can they be measured? Social science information 44, 4 (2005), 695-729.

[31] Scherer, K.R., Shuman, V., Fontaine, J.R., and Soriano, C. The GRID meets the Wheel: Assessing emotional feeling via self-report. Components of emotional meaning: A sourcebook, (2013), 281-298.

[32] Sein, M.K., Henfridsson, O., Purao, S., Rossi, M., and Lindgren, R. Action design research. MIS quarterly, (2011), 37-56.

[33] Seo, M.-G., Barrett, L.F., and Jin, S. The structure of affect: History, theory, and implications for emotion research in organizations. Research companion to emotion in organizations, (2008), 17-44.

[34] Shaw, C. The DNA of customer experience: How emotions drive value. Springer, 2007.

[35] Shaw, C., Dibeehi, Q., and Walden, S. Customer experience: Future trends and insights. Palgrave Macmillan, 2010.

[36] Smith, J.B. and Colgate, M. Customer value creation: a practical framework. Journal of marketing Theory and Practice 15, 1 (2007), 7-23.

[37] Stone, G.P. City shoppers and urban identification: observations on the social psychology of city life. American Journal of Sociology 60, 1 (1954), 36-45.

[38] Suoja, K., Liukkonen, J., Jussila, J., et al. Application for pre-processing and visualization of electrodermal activity wearable data. Proceedings of the EMBEC-NBC2017 Conference, (2017).

[39] Tähtinen, J. and Blois, K. The Involvement and Influence of Emotions in Business Relationships. 26th IMP Conference, Budapest, Hungary, (2010). 